\title{
TEACHER GUIDANCE IN THE IMPLEMENTATION OF CURRICULUM 2013 (K-13) FOR EARLY CHILDHOOD EDUCATION IN THE LANGKAT REGENCY
}

\author{
Sariana Marbun ${ }^{1 *}$, Dorlince Simatupang ${ }^{1}$ \\ ${ }^{I}$ Faculty of Education, Medan State University, Medan, Indonesia \\ *Corresponding Author: sariana.marbun1961@gmail.com
}

\begin{abstract}
The background of the study comes from the low ability of teachers in designing scientific-based learning implementation plan (RPPH) for the Scientific and Local Culture subject and carrying out the authentic assessment for early childhood education (PAUD) students. These activities aim to assist teachers developing Weekly Implementation Plan (RPPM) and RPPH on the aforementioned subject as well as to help teachers developing the authentic assessment instruments in measuring early child development outcomes. The activities were conducted in the Ananda Kindergarten and Early Childhood Education (School Partners) in the Sub-District of Gebang at the District of Langkat from July to September 2017. The participants were teachers in the Partner School and PAUD teachers around the School of Partners, amounting 20 teachers using discussion, questioning, group work and assignment as well as the monitoring and evaluation approaches. The results of the mentoring activities showed that: 1) Most teachers were able to develop RPPM and RPPH based on Scientific and Local Culture, and only a few teachers with senior secondary education background had difficulty in preparing the RPPH according to the guidelines; 2) Most teachers experienced difficulties in developing authentic assessment instruments, 3) Teachers of PAUD were enthusiast engaging in the mentoring activities validated by their presences and activities during processes. The results of these activities recommend that: 1) Do consistent and continuous monitoring of the implementation of learning in accordance with the lesson plans that have been prepared;2) the need for special teacher assistance in the development of authentic assessment instruments for early childhood; 3) The need for special assistance in development and preparation of media and educational game tools in accordance with the needs of early childhood.
\end{abstract}

Keywords: scientific-based learning implementation plan (RPPH), Scientific and Local Culture, early childhood education (PAUD) students, Weekly Implementation Plan (RPPM), District of Langkat

\section{PRELIMINARY}

The curriculum of early childhood that is applied to all PAUD institutions in Indonesia today is stated in the Regulation of the Minister of Education and Culture of the Republic of Indonesia No. 146 of 2014, the Curriculum 2013 PAUD. Curriculum 2013 PAUD aims to encourage the development of the potential of children to have readiness to pursue further education. The characteristics of the Curriculum of 2013 PAUD are: (a) optimizing child development which includes: religious and moral values, physical-motor, cognitive, language, emotional social, and art aspects reflected in the balance of attitude, knowledge and skill competencies; (b) using thematic learning with a scientific approach in the provision of educational stimuli; (c) use authentic assessments in monitoring child development; and (d) empower the role of parents in the learning process.

PAUD educators as the spearhead responsible for learning are expected to be able to design, implement and evaluate activities that involve all aspects of child development so as to achieve the competence of attitudes, knowledge, and skills optimally. Each PAUD educator must understand correctly the curriculum that develops in the education of early childhood, so that the implementation of early childhood education can take place as expected.

The fact shows that not all PAUD institutions can implement the Curriculum 2013 PAUD, as happened in Langkat Regency. In general, teachers are still not well understood in preparing the Weekly Implementation Plan (RPPM) and Daily Learning Implementation Plan (RPPH). Teachers do not understand the basic competencies to be indicators, formulate learning objectives, establish learning materials, choose a scientific based learning strategy, make using or utilizing media and learning resources, teachers lack the understanding to integrate local cultural values in learning that should be written in RPPM and RPPH. Likewise, teachers are still not well understood in designing and implementing assessment of child development outcomes (authentic assemen), so in assessing teachers tend to only assess the work of children, while the process of growth and development of other children less 
attention. such as moral and religious developments, social-emotional, and motoric children who have never taken measurements. Learning tends to still prioritize the success of the academic field of children that is reading, writing and arithmetic, and less attention to the development of other aspects that exist in children. Lessons tend to be done in the classroom and less use the environment as a learning resource.

Advisory activities are aimed at improving teachers' ability to design both Weekly or Local-based Learning Activities and Local Culture as well as being able to implement them in the classroom, as well as being able to develop authentic based assessment instruments and applying them in the classroom.

The PAUD Learning Plan is a written draft of routine children's play activities that describes the structure of activities with play activities. AUD learns well if: a) according to the child's developmental stage; b) according to the special needs of the child; c) Have the opportunity to develop all the potential of the child it has; d) be given opportunities to build knowledge through interaction with playgrounds, friends, adults repeatedly; e) the child feels safe and comfortable psychologically; f) done in an interesting, fun and play manner; g) was introduced early with obedience according to character, religion, social and culture. The design of learning is divided into 3 namely: a) Program Design Semester, b) Weekly Study Implementation Plan; c) Daily Learning Implementation Plan.

The semester program (PROSEM) contains the preparation of learning activities developed from the Basic Competency that contains the content / subject matter to be used in preparing the RPPM, with the composition of the list of themes for one semester and the time allocation set.

The Weekly Implementation Plan (RPPM) is structured as a one-week learning reference. RPPM may take the form of a theme network or other format developed by an early childhood unit containing the content of the material to be developed into a learning activity. RPPM contains the learning content developed from the Basic Competencies listed in the Process according to the theme, sub theme and time allocated. RPPM preparation guidelines are: a) referring to Basic Competence; b) choosing activities in harmony with learning objectives; c) develop child-centered play activities; d) using thematic learning; e) develop a scientific approach to thinking; f) based on local culture and utilizing the surrounding natural environment, as a child media.

Daily Learning Implementation Plan (RPPH) is an activity that will be implemented within one day taken from RPPM. RPPH is developed in accordance with the learning model to be selected eg group model with activity angle, group learning model with safety activities, area learning model, and learning center model. The development of RPPH activities was developed using a scientific approach. The Scientific Approach is a learning process designed in such a way that students are actively developing the competence of attitudes, knowledge, and skills through stages: a) observing; b) questioning; c) collect information; d) reasoning; and e) communicate.

Assessment of early childhood should be authentic. Authentic assessment (authentic assessment) is a significant measurement of the child's learning outcomes for the sphere of attitude, skills and knowledge. Authentic assessment in early childhood is the assessment of process and learning outcomes to measure the level of attainment of attitude competencies (spiritual and social), knowledge and skills are carried out continuously. Assessment not only measures what the child knows, but rather emphasizes what the child can do.

Assessment process and learning outcomes of children in early childhood based on the following principles: 1) Educate; 2) Continuous; 3) Objective: 4) Accountable; 5) Transparent; 6) Systematic; 7) Thorough: and 8) Meaningful. The techniques and instruments used for the assessment of the competence of attitudes, knowledge, and skills are; a) Observation or observation is a valuation technique undertaken during a learning activity either directly or indirectly using an observation sheet, thorough record or journal, and rubric; b) Conversation is a valuation technique that can be used both at the time of the guided and free activities; c) Assignment is a valuation technique in the form of assignment to be done by children in a certain time either individually or group and also independently or accompanied; d) Performance is a judgment technique involving the child in the form of observing an activity that can be observed; e) Assessment of the work is an assessment technique by looking at the products produced by the child after performing an activity; f) Anecdotal recording is an assessment technique undertaken by noting the specific attitudes and behaviors of the child when an event occurs suddenly / incidental both positive and negative; g) Portfolio is a collection or track record of the results of children's activities on an ongoing basis or educator's notes on various aspects of growth and development of children as one of the materials to assess the competence of attitudes, knowledge, and skills.

\section{METHOD OF IMPLEMENTATION}

Teacher assistance activities in the implementation of the curriculum 2013 PAUD implemented in TK Adinda and early childhood Park Akhlak Gebang District Langkat regency, from July to September 2017. Participants of activities as many as 20 teachers, who came from teachers from target schools and teachers that exist in the environment around both PAUD built. The methods implemented during the activities are: Questions, discussions, 
assignments, and simulations. Activities are conducted through three stages, namely; (1) The Preparation Stage; (2) Implementation Phase; and (3) Closing Stage.

Preparatory stage is an activity undertaken to prepare all the needs of mentoring activities such as the preparation of activity schedules, activity materials, data collection instruments, tools needed during the mentoring activities. Implementation is all of the assistance activities conducted to PAUD teachers whose activities are as follows: 1) Question and answer of class discussion about Curriculum 2013 PAUD (Core Competence, Basic Competence and Indicator, development of Early Childhood Learning, Scientific Approach, Local Culture in learning, and authentic assessment of AUD); 2) Assistance in the preparation of Weekly Implementation Plan (RPPM); 3) Assistance in the preparation of Daily Learning Implementation Plan (RPPH) based on Scientific and Local Culture; 4) Advisory Assembling Authentic assessment instruments for AUD. Each completion of the mentoring activities at each step, carried out at the next meeting, so that the teachers know where the shortcomings they do. And so on guidance activities conducted in the same way. The closing stage is the evaluation of process and results and reflection on the tasks that teachers have done during the mentoring.

\section{RESULTS OF DISCUSSION AND DISCUSSION}

The results of activities gained during mentoring are: 1) most teachers already understand the way of preparing the RPPM and RPPH, only in the formulation of the lesson learned lesson teacher formulates the learning objectives of the existing indicators; 2) most teachers understand the meaning of local culture-based learning and are able to identify local cultural values and forms that will be integrated in early childhood learning, only a few teachers with under-skilled secondary education background; 3) most teachers understand the scientific approach and are able to describe every activity undertaken at the stage of observing, questioning, gathering information, reasoning and communicating in early childhood learning activities; 4) most teachers understand the meaning of authentic assessment in early childhood, but only a small proportion of teachers are skilled in developing assessment instruments; teachers are still having difficulty in determining indicators of every aspect that will be assessed in every activity undertaken in the lesson; 5) teachers' motivation to follow activities is very high, this is indicated by teacher attendance at each meeting, and enthusiastic teacher ask questions and responses if done question and answer, and in doing the tasks given.

Advisory activities for PAUD teachers are needed especially for teachers in the region. Based on the standards of PAUD educational staff that early childhood teachers are still allowed to have high school education qualifications and Diploma 2, provided they have a training certificate in accordance with the amount of time set by the government. The number of hours of training to be fulfilled by an early childhood teacher so that the equivalent of a teacher of Strata 1 is intended for teachers to be able to perform their role as professional teachers, such as teachers must be innovative, creative, critical, responsive to existing renewal related to early childhood learning, self, and so forth.

Educators in early childhood are professionals who must have a number of teacher competencies and one of them is the ability to design learning in accordance with the needs of children. Teachers as the spearhead of the curriculum developers should really design the child's learning activities that lead to the development of all aspects of child development. The ability of teachers to design learning activities as required in the Curriculum depends on the ability of teachers to understand and translate all the components in a lesson plan, and the willingness of teachers to implement the curriculum On the other hand, the ability of teachers to understand the changes that occur in the curriculum depends on the level of education and teacher knowledge, training activities that have been followed, and the influence of principals' supervision on teacher performance (Susanto, 2016).

\section{CONCLUSIONS AND RECOMMENDATIONS}

The conclusions that can be drawn from the Curriculum Implementation Assistance activities 2013 in Langkat Regency are as follows:

a. PAUD teachers of partners and other early childhood institutions around Gebang Sub-district generally have been socialized in the Curriculum 2013 of early childhood education, but training specifically for the development of both Semester Program, Weekly Program and Daily Program almost all teachers have never got it.

b. In general, Teacher Assistance activities in the implementation of Curriculum 2013 PAUD succeeded, because teachers are able to prepare RPPM and RPPH with scientific approach although it is still difficult for teachers to choose and establish local cultural materials that must be integrated in Early Childhood Learning.

c. In designing authentic assessment instruments teachers are still experiencing difficulties, so it can be said assistance in this section is still not as expected.

d. Teachers also find it difficult to choose media and tools that can be used in scientific learning, besides teachers are still less skilled in making media and educational game tools that can be used in learning. 
From the conclusions obtained during the mentoring activities, it is advisable:

a. Presumably the results of this activity can be input for PAUD policy makers to improve the quality of teachers, especially in implementing the Curriculum 2013 PAUD.

b. The results of this activity become input for Unimed Community Service Foundation (LPM), especially Lecturer of PG PAUD FIP Unimed to perform Community Service activities, whether in the form of mentoring, workshop or training in improving the professionalism of PAUD teachers in North Sumatra, especially in Langkat Regency.

\section{REFERENCES}

Bagnato, S (2007). Authentic Assessment for Early Childhood intervention: Best practice. New York: NY: Guilford

Collins, R (2013), Authentic assement: assessment for learning. Principals Consultant, Independent Schools Quunsland.

Dockett, Sue and Fleer, Marilyn. (2000). Play and Pedagogy in Early Childhood: Bending the Rules. Sydney: Harcourt Brace.

Permendikbud No 137 of 2014 on the National Standard for Early Childhood Education. Jakarta

Permendikbud No 146 Year 2014 Jakarta About Curriculum 2013 Early Childhood Education. Jakarta

Susanto Ahmad. (2016). Concepts, strategies, and implementation of Teacher Enhancement Management Law No. 20 of 2003 on National Education System. Jakarta.

Law No. 14 Year 2005 on Teachers and Lecturers. Jakarta 